\title{
A flânerie de uma andarilha urbana
}

\author{
Daniela Schrickte Stoll' ${ }^{1}$ (iD 0000-0001-8843-779X \\ 'Universidade Federal de Santa Catarina, Florianópolis, SC, Brasil. 88040-900- \\ ouvidoria@contato.ufsc.br
}

\section{- viref}

\begin{abstract}
Resumo
Neste artigo analisa-se a relação entre a personagem Alice, de Quarenta dias - romance de Maria Valéria Rezende (2014b) -, e a cidade de Porto Alegre, pela qual ela deambula como uma flâneuse contemporânea. A personagem, na realidade, se autodenomina andarilha urbana, já que ela passa a ser uma habitante das ruas. A possibilidade da existência de uma flâneuse mulher é debatida com base nos escritos de Janet Wolff (1985), Griselda Pollock (1988) e Lauren Elkin (2016). Segundo Elkin (2016), a invisibilidade é uma característica fundamental para que alguém desempenhe a flânerie, o que seria inviável para uma mulher, que é sempre objeto do olhar masculino nas ruas. A personagem Alice, no entanto, percebe-se invisibilizada em função de sua idade, de sua origem nordestina e por se tornar uma pessoa em situação de rua ao longo desses quarenta dias. A narrativa também possibilita uma série de reflexões sobre as cidades contemporâneas e as formas de apropriação dos espaços urbanos pelas minorias.
\end{abstract}

Palavras-chave: crítica literária feminista; flâneuse; invisibilidade; literatura brasileira contemporânea; Maria Valéria Rezende.

\section{The Flânerie of an Urban Walker}

Abstract

This article analyzes the interaction between Alice, from Quarenta dias - a novel by Maria Valéria Rezende (2014b) -, and the city of Porto Alegre, in which she wanders like a contemporary flâneuse. The character, in fact, calls herself an urban walker, since she gradually becomes an inhabitant of the streets. The viability of a character such as a female flâneuse is discussed based on the writings of Janet Wolff (1985), Griselda Pollock (1988) and Lauren Elkin (2016). According to Elkin (2016), invisibility is a fundamental characteristic for someone to perform the flânerie, which would be unfeasible for a woman, who is always the object of male gaze on the streets. Alice, however, realizes she is invisible to others, due to her age, her origins and the fact that she becomes a homeless person for forty days. The novel also calls for a series of reflections about contemporary cities and the ways minorities occupy the urban spaces. Keywords: Literary feminist criticism; Flâneuse; Invisibility; Brasilian contemporary literature; Maria Valéria Rezende.

Para escrever o romance Quarenta dias, objeto de análise deste artigo, Maria Valéria Rezende (2014b) passou quinze dias nas ruas de Porto Alegre, fazendo o que a sua personagem, Alice, faria. Em entrevista para o Estadão, ela disse:

Por 15 dias fiz basicamente o que Alice fez. Perguntei para todos onde eu poderia encontrar Cícero Araújo, que era invenção minha, e ia atrás dele. Voltava para casa à noite, mas cheguei a dormir em rodoviária, aeroporto e hospital, onde tinha abrigo, porque uma velhinha de 70 anos não pode abusar e eu não estava para fazer sacrifício da minha vida por causa de uma ideia de romance. [...]. Nessas andanças, percebi que metade do mundo é feita de gente sumida e a outra metade está procurando quem sumiu - não apenas aqueles que foram para a rua, mas também os que não quiseram mais dar notícia (Maria Valéria REZENDE, 2014a).

Essa experiência pode ter sido fundamental para a construção do romance, que faz uma série de referências a locais existentes e marcos urbanos da cidade de Porto Alegre, com os quais 
a personagem interage ao longo de toda a história. Neste artigo, será feita uma análise dessa relação entre a personagem Alice e a cidade, e dos papéis da personagem entre o de flâneuse e o de andarilha urbana.

Em Quarenta dias (2014b), a professora de francês aposentada chamada Alice se muda a contragosto de João Pessoa para Porto Alegre, a pedido da filha Norinha, que planejava ser mãe. Norinha queria que Alice se tornasse avó em tempo integral. Assim, Alice deixa para trás um lar esvaziado, também a contragosto, após arrastarem móveis, alugarem caminhonetes e botarem cartazes de "família-vende-tudo" (REZENDE, 2014b, p. 8). Em Porto Alegre, Alice não se identifica com o novo lar montado pela filha: "entrei neste apartamento - ainda não consigo dizer 'em casa', tento, mas não há jeito” (REZENDE, 2014b, p. 13). Pelo contrário, ela demonstra grande estranheza: "metida nesta cozinha alheia, 'showroom' de móveis modernosos, com minha angústia e meu desacerto" (REZENDE, 2014b, p. 23). O novo apartamento é decorado em preto e branco, o que faz Alice chamá-lo de tabuleiro de xadrez - a filha dela seria, assim, a Rainha Louca que a controla como a um peão. Um desentendimento entre as duas (Norinha muda de planos, decide deixar a mãe sozinha em Porto Alegre e viajar para a Europa para realizar uma pesquisa que poderia levar até oito meses) faz com que Alice saia para a rua, sem destino. É assim que ela se torna uma andarilha urbana durante quarenta dias. Quando retorna ao apartamento, ela relata a experiência por escrito, em formato de diário, num caderno pautado com a capa da Barbie. A Barbie se torna sua interlocutora, e esse diário é o romance que se apresenta ao/à leitor/a.

Alice sai pelas ruas, inicialmente, motivada pela busca por Cícero Araújo, um conterrâneo desaparecido em Porto Alegre. Seu deslocamento, tomado como de uma flâneuse contemporânea, resignificaria o próprio sentido da flânerie, já que o flâneur sempre foi um personagem tipicamente masculino da modernidade: o rapaz ocioso que vagueia pela rua sem pressa, olhando, vendo, refletindo - o surgimento do flâneur esteve ligado ao surgimento do urbanismo, com imensas aglomerações de seres humanos com detalhes variados (James WOOD, 2012).

Charles Baudelaire (1821-1867) foi o poeta francês conhecido por explorar as transformações que as cidades sofriam na modernidade, retratadas através do olhar do flâneur. Sobre sua obra, o filósofo e sociólogo alemão Walter Benjamin (1892-1940) escreveu diversas análises. Para Benjamin (1994), o flâneur era uma espécie de "botânico do asfalto". Antes das intervenções urbanísticas do barão Haussmann, que abriu largas avenidas em Paris, praticamente não existiam passeios largos na cidade francesa, portanto as passagens cobertas, galerias comerciais com coberturas de vidro e revestimentos de mármore que atravessavam blocos de casas eram o local de deambulação do flâneur. Mais tarde,

a rua transforma-se na casa do flâneur, que se sente em casa entre as fachadas dos prédios, como o burguês entre as suas quatro paredes. Para ele, as tabuletas esmaltadas e brilhantes das firmas são adornos murais tão bons ou melhores que os quadros a óleo no salão burguês; as paredes são a secretária sobre a qual apoia o bloco de notas; os quiosques de jornais são as suas bibliotecas e as esplanadas as varandas de onde, acabado o trabalho, ele observa a azáfama da casa (Walter BENJAMIN, 1994, p. 39).

Benjamin afirmou que, durante algum tempo, por volta de 1840, era "de bom tom" levar tartarugas para passear. O flâneur deixava que elas ditassem o ritmo dos seus passos. "Ocioso, deambula como uma personalidade, protestando contra a divisão do trabalho que transforma as pessoas em especialistas" (BENJAMIN, 1994, p. 55).

Para Griselda Pollock (1988), teórica feminista radicada na Inglaterra, a modernidade foi um fenômeno do século XIX e um produto da cidade. Ela correspondeu a um aumento populacional nas cidades, que levou a uma literatura das massas, da aceleração e da moda. Houve uma mudança de caráter das cidades, que deixaram de ser centros de atividades visíveis (manufatura, troca, comércio) para ser zoneadas e estratificadas, com a produção menos visível. Assim, o centro de cidades como Paris e Londres se tornou local de consumo, de vitrines, produzindo o que o sociólogo e historiador estadunidense Richard Sennett (1988) chamou de cidade do espetáculo. Segundo Pollock (1988), não seria possível uma flâneuse mulher, na época: o flâneur simbolizava o privilégio da liberdade de se mover em arenas públicas da cidade, observando, mas nunca interagindo, consumindo os locais através de um olhar direcionado tanto para as outras pessoas como para os produtos à venda. Para a autora, "o flâneur encarna o olhar da modernidade cobiçoso e erótico"' (Griselda POLLOCK, 1988, p. 67 [tradução minha]).

De acordo com Richard Sennett (1988, p. 183), nas últimas décadas do século XIX, os/as donos/as das lojas de departamentos começaram a trabalhar mais o caráter de espetáculo de suas empresas. Vitrines envidraçadas foram inseridas nos andares térreos das lojas e suas decorações tornaram-se cada vez mais fantásticas e elaboradas.

Desde o final do século XVIII, a emergente burguesia contestava a dominância da formação social aristocrática. Em busca de liberdade, igualdade e fraternidade, imaginava uma sociedade

\footnotetext{
1 "The flâneur embodies the gaze of modernity which is both covetous and erotic".
} 
composta por homens livres e independentes, o que acreditava que a definia como universalista e democrática. Conforme a análise de Pollock (1988, p. 67), a própria condição de existência econômica da burguesia, enquanto classe, era estruturada na desigualdade socioeconômica e de gênero. Para tanto, utilizavam duas estratégias: a primeira era a naturalização de diferenças de classe, raça e gênero; a segunda era a divisão em esferas pública e privada, que acontecia em nível ideológico e também em forma de regulação das práticas de homens e mulheres.

Janet Wolff (1985), nascida no Reino Unido e professora radicada nos Estados Unidos e autora de obras sobre a sociologia da arte e da cultura, também afirmou que, mesmo que houvesse mulheres na esfera pública, no mundo do trabalho, da política e da cidade, elas ainda eram chefiadas por homens, ou seja, essas áreas ainda eram dominadas por eles em termos de estrutura hierárquica. Além disso, mesmo quando havia mulheres circulando pelas ruas, a separação entre o público e o privado era ideológica e permeava a sociedade (Janet WOLFF, 1985, p. 34). Aquelas que saíam às ruas não eram tidas como respeitáveis. Sennett (1988, p. 39) igualmente afirmara que a rua era onde elas corriam o risco de perder a virtude. Na obra de Baudelaire, segundo Wolff, as mulheres que aparecem são a prostituta, a viúva, a velha, a lésbica, a vítima de assassinato e a mulher passante desconhecida (alvo do olhar do flâneur). Algumas têm traços masculinos Wolff (1985, p. 42) explica que, segundo Benjamin, a admiração que Baudelaire sentia pelas lésbicas teria a ver com a masculinidade delas.

Por outro lado, os homens que saíam em público no século XIX "eram capazes de se retirar dessas mesmas características repressivas e autoritárias da respeitabilidade que se supunha estarem encarnadas na sua pessoa, enquanto marido e pai, no lar" (SENNETT, 1988, p. 39). Para Wolff, portanto, a literatura da modernidade descreve a experiência dos homens. "É essencialmente uma literatura sobre transformações no mundo público e na consciência associada a esse mundo"2 (WOLFF, 1985, p. 34 [tradução minha]).

Mesmo antes de Pollock (1988) e Wolff (1985) refletirem a respeito do espaço da mulher na literatura da modernidade, a escritora britânica Virginia Woolf (1985) já havia chamado atenção para a vivência doméstica das escritoras do século XIX (como exemplo, ela cita Charlotte Brontë, Jane Austen, Emily Brontë e George Eliot), muito diferente da vivência dos homens, que circulavam livremente pelos espaços públicos. As mulheres, segundo Woolf, além de serem desencorajadas a escrever e de não contarem com dinheiro próprio para se sustentar, quando ousavam escrever, tinham suas histórias diminuídas por se tratar de pontos de vista domésticos. As mulheres negras, ainda que ausentes na reflexão de Woolf, circulavam pelas ruas da Europa e das Américas nesse mesmo período, mas eram proibidas de ler e escrever, porque eram escravizadas. Não se sabe qual a percepção delas sobre a cidade, ainda que, desde o século XIX, se conheça o que os escritores homens formularam sobre o espaço urbano: Balzac, Dostoiévski, Baudelaire, entre outros. Para Regina Dalcastagnè (2003), se não sabemos como as mulheres veem e se relacionam com esse espaço, elas se tornam invisíveis, "são apagadas de nossas ruas, praças, prédios públicos como se nada tivessem a fazer ali, como se nada tivessem a dizer da vida nesses lugares" (p. 46).

Assim sendo, na contemporaneidade, seria possível uma flâneuse? Seria Alice, de Quarenta dias (2014b), uma flâneuse contemporânea?

Segundo Lauren Elkin (2016), professora estadunidense na área de Língua Inglesa, a flânerie não significa universalmente liberdade e lazer; ela pode ser a experiência de alguém que segue uma outra pessoa. Aproximando essa ideia ao romance de Maria Valéria Rezende, nota-se, justamente, que os deslocamentos de Alice pelas ruas seguem os rastros de Cícero Araújo. Muitas vezes, são rastros e motivações que ela inventa:

Fingia que dormia, as pálpebras entreabertas, mas espiava tudo e todos os que cabiam no meu raio de visão, rasteiro, até sentir que era hora de me mexer de novo, andar, continuar para qualquer direção, achar ou inventar novas pegadas de Cícero Araújo (REZENDE, 2014b, p. 165).

Isso também se verifica nesta passagem, mais próxima do final da narrativa, quando ela já não depende tanto de Cícero Araújo para inventar seus caminhos:

\begin{abstract}
Já então eu sabia que andava por andar, por vilas, ruelas, becos e acampamentos de operários, ao léu, a qualquer lugar a que me conduzisse o ônibus que calhasse, dormitando embalada pelo sacolejo do veículo ou mirando vagamente a paisagem incógnita, as mesmas casinhas com grades e jardinzinhos, as mesmas, sempre as mesmas avenidas exageradamente largas pra meu olhar paraibano, me perguntando, aqui e ali, o que era 'brique', o que era isso ou aquilo que eu via escrito em placas por toda parte sem descobrir o significado, por que será que tem tanta casa funerária nesta cidade?, andava só pra não voltar, eu, rebelde peão de xadrez a correr atrás de um peão de obra imaginário, a ouvir histórias de gente quase reduzida a corpo e dor, quase (REZENDE, 2014b, p. 218).
\end{abstract}

Segundo Elkin (2016), o argumento contra a possibilidade da existência da flâneuse é a visibilidade, pois é crucial que o flâneur seja invisível na multidão, para ter sua liberdade de ir e

\footnotetext{
2 "It is essentially a literature about transformations in the public world and in its associated consciousness".
} 
vir, assim como de observar anonimamente. Para Pollock (1988), as mulheres do século XIX não desfrutavam da liberdade de serem anônimas na multidão. Elas nunca estavam posicionadas como ocupantes normais do espaço público, não tinham o direito de olhar, encarar, examinar. Mas a invisibilidade não é um problema para Alice:

Ninguém reparava em mim, talvez efeito dos meus cabelos que teimo em deixar grisalhos apesar da incansável insistência da Elizete. Credo, Alice, que desleixo!, nem parece que você é uma mulher inteligente e estudada, acha certo parecer uma velha bem antes mesmo de entrar nos sessenta? [...] (REZENDE, 2014b, p. 99).

Primeiro, sua invisibilidade era fruto da idade, pois as mulheres só são olhadas e consideradas atraentes enquanto jovens e dentro dos padrões de beleza impostos pela sociedade. Depois, no final do romance, quando já se acostumou ao papel de andarilha urbana sem lar, ela passa a se vestir como Lola, uma habitante das ruas que se torna sua amiga, o que faz com que Alice acredite ter se tornado totalmente invisível, enfim:

Vesti as três camisas, uma por cima da outra, e amarrei na cintura o casaco de lã ruço, cheio de bolinhas, acabando de conquistar a total invisibilidade que eu desejava. Segui, assim, sentindome então mais confortável pra meter-me nas pequenas brechas da cidade (REZENDE, 2014b, p. 219).

De acordo com Pollock (1988, p. 71), nos textos de Baudelaire, as mulheres não olhavam, elas estavam posicionadas como objeto do olhar do flâneur. A mulher era um objeto de análise e observação tanto quanto a cidade o era. A crítica de Pollock (1988, p. 85) às histórias da arte conclui que a espectadora feminina foi completamente negada na tradição seletiva que nos foi oferecida como história.

Nas ruas, as mulheres do século XIX eram escrutinadas pelas roupas como forma de determinar a classe social a que pertenciam, de acordo com Wolff (1985, p. 41). Elas não podiam flanar sozinhas pela cidade (WOLFF, 1985, p. 41). A autora também acredita que a flâneuse era uma personagem impossível naquela época.

Já na contemporaneidade, a ideia de uma mulher na rua ainda levanta o questionamento: ela pode ser uma flâneuse despreocupada, se é objeto do male gaze, o olhar masculino? O termo male gaze foi cunhado por Laura Mulvey (1990) em ensaio sobre o protagonismo do olhar masculino no cinema mainstream, ${ }^{3}$ mas a pergunta acima foi colocada por Elkin (2016), diante da fotografia intitulada An american girl in Italy [Uma menina americana na Itália], que retrata Jinx Allen nas ruas de Florença, ainda em 1951. A fotografia, tirada por Ruth Orkin, ficou conhecida porque retrata esse problema. As amigas passeavam na cidade e alegam que se divertiram - elas não consideram a foto um símbolo de assédio. No entanto, é impossível negar a dominância masculina do espaço, o conforto com que os homens assediam, se impõem no caminho delas e fazem uso do male gaze, assim como é notável o desconforto na expressão de Allen.

O problema persiste na contemporaneidade: a atriz estadunidense Shoshana Roberts, em 2014, propositalmente andou pelas ruas de Nova lorque atrás de uma câmera escondida, que registrou a atriz sendo assediada 108 vezes em dez horas. O vídeo, intitulado "10 hours of Walking in NYC as a Woman [dez horas andando em Nova lorque como uma mulher]" (Robert BLISS, 2014), foi postado na plataforma YouTube e visualizado por milhares de pessoas.

Assim, se é impossível para as mulheres serem invisíveis nas ruas, onde são sempre objetos do olhar masculino, seria impossível que se tornassem flâneuses. É por isso que Pollock (1988, p. 66) se refere a uma política sexual do olhar que demarca uma organização social particular do olhar e mantém a ordem social da diferença sexual. Dentro dessa política, são moldados os espaços de feminilidade, que são produtos de uma percepção de localização, mobilidade e visibilidade nas relações sociais de ver e ser visto.

Em Quarenta dias (2014b), no entanto, fica clara a invisibilidade de Alice, ao se tonar uma habitante das ruas - assim como de outras pessoas, invisíveis para a cidade por sua condição marginalizada - e o quanto a personagem adota a prática da flâneuse de "espiar":

Pra onde ir?, por enquanto, pra lugar nenhum, continuar escondida ali, invisível entre os invisíveis com suas garrafas térmicas e suas cuias de chimarrão, espiando, por todo o tempo que eu

\footnotetext{
${ }^{3}$ Segundo Mulvey (1990), em um mundo comandado pelo desequilíbrio entre os gêneros, o prazer de olhar foi separado em ativo/masculino e passivo/feminino. O male gaze, o olhar masculino, projeta suas fantasias nas figuras femininas, que são representadas no cinema como objetos para serem exibidos e olhados. As mulheres representadas como objetos sexuais são a ideia dominante do espetáculo erótico, que é indispensável para a narrativa de um filme comercial. A presença dessas mulheres nas narrativas, segundo Mulvey, não serve para desenvolver a história, mas para momentos de pausa na ação para possibilitar a contemplação erótica. Em contrapartida, as figuras masculinas dão vida e movimento à história, que acompanha o ponto de vista dos protagonistas homens, pressupondo espectadores masculinos. Desde a publicação do ensaio de Mulvey, diversas críticas apontaram a forma como o male gaze não se restringe ao cinema, ocorrendo igualmente em outras formas de representação, como a literatura, e conferindo aos homens um espaço de protagonistas do olhar também em espaços fora das narrativas, como as calçadas.
} 
quisesse, aquele pedaço de mundo no qual tudo que a cidade quer esconder abre-se como um abscesso supurado (REZENDE, 2014b, p. 150).

Na contemporaneidade, alguns indivíduos não passeiam pelas ruas movidos pelo que motivava o flâneur do século XIX - o ócio. Segundo o crítico literário uruguaio Hugo Achugar (2008), são pessoas em situação de rua, pessoas excluídas do consumo por carecer de emprego ou por terem sido expulsas de seu país como migrantes, pessoas que executam trabalhos que os cidadãos não querem executar. São os sujeitos que Zygmunt Bauman (2005), sociólogo polonês falecido em 2017, chamou de "consumidores falidos" ou "consumidores falhos".

Não se trata mais de ócio, mas de exclusão, expulsão. Assim, cabe o questionamento de Achugar (2008) sobre a diferença nos modos de olhar para a cidade entre o flâneur e os/as "consumidores/as falidos/as". "Experimentam a velocidade do mesmo modo? O fragmentário tem o mesmo sentido para ambos? Se deslocam na mesma velocidade e nos mesmos meios de transporte? Consomem igual?"4 (ACHUGAR, 2008 [tradução minha]). Para o autor, o flâneur tem o olhar como centro, e os/as excluídos/as têm um "olhar falido", de acordo com a sociedade de consumo do presente. O primeiro é consumidor e cidadão, os/as outros/as não. Os/as "consumidores/ as falidos/as", o/a "catador/a de papel", o/a "revirador/a de lixo", ao contrário do flâneur, não interiorizam a paisagem urbana como algo do qual fazem parte. Eles/as buscam na cidade contemporânea algo diferente do que os/as consumidores/as e cidadãos/ãs buscam. Estes/as recorrem aos shopping centers em busca do objeto que vai saciar sua necessidade de consumo, a mais recente novidade da tecnologia contemporânea, enquanto aqueles/as recorrem à cidade em busca das sobras que os/as consumidores/as tenham descartado (ACHUGAR, 2008).

A cidade da contemporaneidade, segundo Achugar (2008), não é mais um lugar onde se vagueia, mas onde as pessoas se deslocam aceleradamente de novidade em novidade. Assim, o presente parece deixar de fora uma grande parte de habitantes do planeta, consistindo numa divisão entre aqueles/as que consomem as novidades e aqueles/as para quem as novidades são apenas espetáculo. É a diferença entre comer e assistir a outro/a comer. Ter a experiência e contemplar a experiência de outro/a (ACHUGAR, 2008).

Para o antropólogo argentino Néstor Canclini (2002),

do passeio do flâneur que reunia informações sobre a cidade para depois transferi-las às crônicas literárias e jornalísticas, passamos, em cinquenta anos, ao helicóptero que sobrevoa a cidade e oferece a cada manhã, através da tela do televisor e das vozes do rádio, o panorama de uma megalópole vista em conjunto, sua unidade recomposta por quem vigia e nos informa (p. 41).

O autor argumentou que a expansão irracional e especulativa provocou uma urbanização que desurbaniza, repleta de desequilíbrios e incertezas. Locais como centros históricos e praças, que mantinham viva a memória e permitiam o encontro das pessoas, perderam força diante da remodelação dos imaginários operada pelos meios de comunicação.

Os relatos mais influentes sobre o que significa a cidade emergem agora da imprensa, do rádio e da televisão. No tumulto heterogêneo e disperso de signos de identificação e referência, os meios não propõem tanto uma nova ordem, mas sim oferecem um espetáculo reconfortante (CANCLINI, 2002, p. 42).

É por isso que, em Quarenta dias, Alice sente que penetrou no "avesso da cidade", uma realidade paralela que era invisível para quem habita a superfície:

Continuei por semanas minha romaria pelo avesso da cidade, explorando livremente todas as brechas, quase invisíveis pra quem vive na superfície, pra cá e pra lá, às vezes à tona e de novo pro fundo, rodoviária, vilas, sebos e briques, alojamentos, pronto-socorro, portas de igrejas, de terreiros de candomblé, procurando meus iguais, por baixo dos viadutos, das pontes do arroio Dilúvio, nas madrugadas, sobrevivente, sesteando nas praças e jardins, debaixo dos arcos e marquises, sob as cobertas das paradas de ônibus desertas, vendo o mundo de baixo pra cima, dos passantes apenas os pés (REZENDE, 2014b, p. 235).

Quando Alice faz referência ao avesso da cidade, coloca em questão essa polarização entre a cidade da superfície (do espetáculo, da velocidade, do consumismo, da Barbie) e a cidade do avesso (onde habitam as identidades excluídas e marginalizadas).

De acordo com Bauman (2005), não apenas a modernidade produziu montanhas de lixo, como também produziu "refugo humano": seres humanos "refugados", "excessivos", que são um efeito colateral do "progresso econômico" e da "construção da ordem" - e cada ordem define algumas parcelas da população como "deslocadas", "inaptas" ou "indesejáveis" (p. 12).

Essa análise vai ao encontro da crítica de Alice, em Quarenta dias (2014b), que, depois de ter se juntado às pessoas em situação de rua (os refugos humanos), escreve ironicamente no caderno com capa da Barbie (símbolo do consumismo e da superficialidade).

\footnotetext{
4 "¿Experimentan la velocidad del mismo modo? ¿Lo fragmentario tiene el mismo sentido para ambos? ¿Se desplazan
} a la misma velocidad y en los mismos medios de transporte? ¿Consumen igual?". 
Fiquei chateada de que [Lola] me acreditasse igual a ela, sim, moradora de rua, pedinte, arrastando aquele carrinho enferrujado afanado na porta de um supermercado qualquer ou recuperado no ferro-velho, empanturrado de sobejos do consumismo dos outros, de todo tipo, equilibrando milagrosamente uma montanha maior que ela de latinhas de refrigerante e garrafas pet amassadas, folhas de papelão, montes de trapos escapando pelas aberturas da grade do carrinho, um vulto a mais dos muitos semelhantes que eu já tinha entrevisto por ali, como coisas das ruas, sem lhes conceder mais atenção do que a um banco de praça, uma lixeira, um orelhão inútil. A rua é cheia de coisa sem muita serventia, Barbie, do mesmo jeitinho que os quartos de meninas de hoje que você costuma frequentar, só o preço é que difere (REZENDE, 2014b, p. 196 [grifos meus]).

Nesse trecho, a personagem está alinhada com as análises de Bauman. Percebe-se que seu olhar para a experiência nas ruas é crítico. Há uma comparação entre as pessoas em situação de rua e a Barbie, ambas como "coisas sem serventia" - as primeiras são descartáveis porque não podem consumir, a segunda é descartável porque é um objeto de consumo, substituído por uma novidade a cada dia. "Esse é, em linhas gerais, o ambiente da vida contemporânea. Os 'problemas do refugo (humano) e da remoção do lixo (humano)'” (BAUMAN, 2005, p. 14).

Segundo Bauman (2005), "removemos os dejetos da maneira mais radical e efetiva: tornandoos invisíveis, por não olhá-los, e inimagináveis, por não pensarmos neles" (p. 38). A "população excedente" é mais uma variedade do refugo humano. São "baixas colaterais, [...] não intencionais e não planejadas, do progresso econômico" (BAUMAN, 2005, p. 53). Em obra posterior, Bauman (2009) nomeou esses sujeitos como "supérfluos", porque, segundo ele, não é correto dizer que estejam em excesso, uma vez que sua exclusão agora é permanente. Se, antes, essa população era constituída por gente "'em excesso', temporariamente excluída e ainda não reintegrada, que a aceleração do progresso econômico havia privado de 'utilidade funcional'" (p. 6), mais recentemente passaram a ser "consideradas incapacitadas para a reintegração e classificadas como não-assimiláveis" (p. 6), o que faz essas pessoas serem vistas como uma "classe perigosa" (BAUMAN, 2009, p. 6). Para o autor, é justamente a irrevogabilidade dessa situação, uma consequência direta da decomposição do Estado social, que transforma os/as excluídos/as em "classes perigosas" (BAUMAN, 2009, p. 6). Além disso, as pessoas "supérfluas", muitas vezes, são obrigadas a deslocarem-se, como é o caso dos/as refugiados/as.

Enquanto isso, na cidade da superfície, as pessoas se deslocam em seus trajetos precisos e velozes até o trabalho e de volta para casa, aquelas pessoas que de fato são tidas como cidadãs e consumidoras, conforme mencionado por Achugar (2008). Delas, Alice vê apenas os pés que passam.

De acordo com Mabel Piccini (2003), que foi uma professora argentina exilada no México,

parece que o espaço urbano converteu-se em lugar de trânsito e de passagem entre um lugar e outro, entre zonas de produção e localizações de vida cotidiana, entre um espaço de lazer e o regresso para casa. Talvez não seja exagerado dizer, em certo sentido, que os eixos viários, projetados como rotas velozes para o trânsito rápido, representam a metáfora mais expressiva da circulação da energia urbana: trata-se de chegar, não de se deter; de circular e não de passear ou perambular. Assim, a arte de deslocamento dos habitantes da capital é, no melhor dos casos, ir e vir por rotas pré-fixadas para lugares pré-fixados. A possibilidade de contato com a cidade e com os outros está a tal ponto restrita a rotinas fixas que a 'liberdade de mobilizar-se', o 'direito à cidade' e até o simples fato de conhecê-la - e habitá-la - reduzem-se dia a dia (p. 6).

Por fim, além das invisibilizações já abordadas neste artigo (essenciais para que a personagem se torne uma flâneuse), o romance traz ainda uma terceira forma de invisibilização: além de idosa e habitante das ruas, Alice é também nordestina. Isso aparece desde o início, sempre que Alice é chamada de "brasileirinha" pelos/as porto-alegrenses, um estereótipo que era aplicado a todos/as de origem nordestina, identidade deduzida de acordo com a aparência, a cor da pele e o sotaque. A maioria dos/as nordestinos/as que Alice encontra na cidade estava na periferia e nos alojamentos da construção civil - já segregados/as urbanisticamente e socialmente. Havia ainda a homogeneização das suas identidades - paraibanos/as, baianos/as, recifenses eram todos/as de "lá": "'lá' parecia ser um vago território homogêneo que cobria tudo o que fica acima do Trópico de Capricórnio" (REZENDE, 2014b, p. 110-111).

Quando retrata a realidade das periferias de Porto Alegre, nos trechos em que Alice procura por Cícero Araújo nas Vilas, como são chamadas as favelas no local, o romance explicita a segregação social e urbana das pessoas negras e das nordestinas:

Lá fui me metendo pela Vila que quanto mais subia mais ar de favela tinha, eu com minha guia, Adelaida, que parecia conhecer o território como a palma da mão e emburacava por tudo que era beco cuja entrada eu nem tinha percebido, chamava alguém pelo nome, ou batia palmas chamando qualquer um que aparecesse, entrava por todo comércio e bar que havia no caminho, Vamos lá na Associação, Vamos lá na sede do Movimento tal, do Centro não sei do quê, Banheiro?, é melhor lá na escola, acabou?, agora falta perguntar na igreja essa, na outra e mais outra, no ilê Pai de tal, no abassá de Mãe fulana, eu espantada de ver tantos negros e 
tanto terreiro de religião afro nesse mundo sulino, antes, pra mim, quase todo louro "como os trigais" de não sei onde (REZENDE, 2014b, p. 116).

Segundo o pesquisador Leandro Pinheiro (2016), Porto Alegre tem cerca de 13,7\% de sua população vivendo em aglomerados subnormais (dados do Censo de 2010). Para efeito de comparação, ele acrescenta que a proporção, na cidade de São Paulo, é de 11,4\%. O déficit habitacional, na capital gaúcha, é de 38 mil unidades, segundo Pinheiro (2016). As Vilas (ou favelas) são realidades complexas e heterogêneas, com diferentes organizações socioespaciais, políticas e culturais. Formadas, em sua maioria, desde o início do século XX (época de políticas de higienização), as periferias cresceram, sobretudo, a partir dos anos 1960 e 1970 com os movimentos migratórios do campo para a cidade, assim como em outras cidades brasileiras (Leandro PINHEIRO, 2016). Percebe-se o fator étnico-racial da segregação, como no trecho acima, de Quarenta dias (2014b), e também segundo os dados fornecidos por Pinheiro (2016): "para [os bairros] Bom Jesus, Mario Quintana e Restinga, mais de 38\% dos habitantes são autodeclarados negros (ao passo que este índice é de $20 \%$ para o conjunto da cidade)".

A respeito de mobilidade e apropriação da cidade, Pinheiro (2016) afirma que:

De toda forma, a apropriação da cidade remete à participação em relações de poder. São comuns as reclamações de moradores das periferias relativas ao preconceito quando buscam emprego, transitam pelas ruas, são noticiados na mídia ou abordados pela polícia. A articulação entre repressão (policial), estigmatização e empobrecimento segue operando fortes restrições a uma relação de mais fruição da urbe. Neste cenário, a disputa pela cidade é ambiência de táticas e de reforço das redes de identificação.

Esse argumento mostra como a fruição da cidade pode ser diferente para os diversos grupos, o que corrobora a ideia de que a flânerie não é uma possibilidade igual e acessível a todos/as. O direito à cidade, assim, é um conceito fundamental para esta reflexão. Teorizado pelo geógrafo britânico David Harvey (2013), o conceito de direito à cidade foi assim definido pela advogada popular e mestranda em Direito Urbanístico, Vanessa Koetz (2017):

O direito à cidade é a apropriação direta dos citadinos a fim de superar a lógica do mercado e reafirmar a cidade como proveito para seus habitantes, exprimindo-lhe um novo significado construído coletivamente, a partir dos desígnios humanos e não do Capital (p. 76).

Para Koetz (2017), que trabalha o conceito de direito à cidade a partir de um ponto de vista feminista, a luta das mulheres - por segurança, por mais creches e centros de educação infantil, pelo direito de fazer política, pelo direito de ocupar as ruas como espaços de convívio e não apenas de passagem - é também uma luta pelo direto à cidade. Ela assinala a importância das manifestações feministas ao tomarem as ruas, já que fazem com que as ruas e as praças, lugares de circulação, sejam apropriadas e virem a expressão imediata da política. Esse gesto de ocupar as ruas, espaço tradicionalmente masculino, é muito significativo por ser também uma forma de as mulheres se posicionarem como sujeitos políticos e como cidadãs.

Outras pesquisas, que também desenvolveram análises urbanas através de perspectivas de gênero, classe, raça e orientação sexual, apresentaram dados importantes para se pensar o direito à cidade: segundo a espanhola Inés Madariaga (2004), por exemplo, ao circular pelos espaços urbanos, as mulheres se deslocam para o mercado, a creche, o parque e o posto de saúde com maior frequência que os homens. Ou seja, os deslocamentos das mulheres, na vida real, costumam envolver não apenas a ida ao trabalho, mas também as atividades relacionadas ao cuidado do lar e dos filhos - a tripla jornada feminina. Um estudo realizado pela Secretaria Municipal de Desenvolvimento Urbano de São Paulo (2016) obteve dados semelhantes aos mencionados pela pesquisadora espanhola, mesmo em espaços e temporalidades distintas. A SMDU concluiu ainda que as mulheres usam mais o transporte coletivo e andam mais a pé do que os homens, justamente os espaços em que elas relatam sofrer assédio e intimidação. Mas isso não ocorre igualmente entre todas elas: uma pesquisa realizada pelo Fórum Brasileiro de Segurança Pública e pelo Datafolha (2017) mostrou que as mulheres negras relatam sofrer assédio com mais frequência do que as brancas - e o tipo de assédio mais comum é receber comentários desrespeitosos ao andar na rua, mas elas também relataram sofrer assédio físico em transporte público. Muitas vezes, as mulheres se deslocam com medo ou evitam determinados lugares. Algumas delas, ainda, sofrem violências específicas nas ruas: segundo a Comisión Interamericana de Derechos Humanos (2014), a maioria dos casos de violência não letal contra mulheres lésbicas e bissexuais são ataques contra casais em lugares públicos. Já as mulheres transexuais são as principais vítimas de assassinato - e seus cadáveres são mais frequentemente encontrados nas ruas, ao contrário de outros crimes de caráter doméstico. Ou seja, as minorias precisam constantemente lutar pelos seus direitos de existir, de se deslocar e de ocupar a cidade, de modo que existem vários fatores a se considerar quando se pensa na possibilidade (ou não) de uma flânerie feminina. 
Além disso, em Quarenta dias, percebe-se que a "cidade da superfície", que marginaliza e invisibiliza identidades, é também uma cidade gendrada. Nela, as ruas têm nomes de homens, como observado por Alice: "Nem sei mais quantas vezes levei ao Borges, ao Bento, ao Protásio, ao Nilo, ao Osvaldo a minha desaparência" (REZENDE, 2014b, p. 235). Antônio Augusto Borges de Medeiros, Protásio Antônio Alves, Nilo Procópio Peçanha e Osvaldo Euclides de Sousa Aranha foram políticos brasileiros. Bento Gonçalves da Silva foi um dos líderes da Revolução Farroupilha. Ainda que as mulheres também tenham feito história, política e literatura, elas não são homenageadas em placas e monumentos na mesma medida. Conforme aponta a arquiteta e urbanista brasileira Joice Berth, citada em reportagem de Carolina lto (2017), a "homenagem" às mulheres aparece de outra forma, como se viu na declaração do arquiteto Oscar Niemeyer (19072012), ao afirmar que suas obras de formas arredondadas eram tributos às curvas do corpo feminino, o que é, mais uma vez, objetificação. Assim, os espaços das cidades podem fazer as mulheres se sentirem livres e autorizadas ou, ao contrário, objetificadas, ignoradas, banidas.

Em Porto Alegre, os nomes de mulheres aparecem em proporção muito inferior. Algumas, no entanto, chamam atenção, como a Rua Anita Garibaldi (catarinense que lutou na Revolução Farroupilha, na Batalha dos Curitibanos e na Batalha de Gianicolo, na Itália), o Alto da Bronze (que faz menção a uma prostituta apelidada de Bronze) e o Arraial da Baronesa (território negro de Porto Alegre que faz menção à antiga proprietária daquelas terras, a Baronesa de Gravatahy). Predominam, porém, como em outras cidades, os nomes de homens.

Segundo Elkin (2016), os nomes que as cidades exibem nos seus pontos de referência, especialmente nas ruas, são reflexos dos valores da época. Houve um período em que as ruas tinham nomes de mulheres - santas, realezas, figuras míticas - que foram substituídas na era moderna por nomes de homens - heróis democráticos, intelectuais, cientistas, revolucionários - no esforço de tornar o espaço público menos associado à religião, ao privado e ao tradicional e mais associado à democracia. Conforme explica a autora, quando as mulheres aparecem - e não é frequentemente; por exemplo, segundo ela, existem duas vezes mais estátuas de cachorros em Edimburgo do que de mulheres - são idealizadas, moldadas em pedra como alegorias ou escravas. Há estátuas que são disputadas, não se sabe se representam a amante de Victor Hugo ou de Gustave Flaubert. Há estátuas que seguram prédios inteiros (as cariátides, estátuas de mulheres que servem de colunas em prédios de Paris) e, no entanto, continuam delicadas e elegantes. A questão das estátuas e dos nomes das ruas mostra o caráter gendrado dos espaços das cidades, como observado também pela geógrafa inglesa Doreen Massey (2009), autora de Space, place and gender [Espaço, lugar e gênero]: a generização dos lugares reflete e tem efeito na maneira como o gênero é construído e entendido nas sociedades em que vivemos.

Em oposição a essa cidade da superfície - gendrada, consumista, produtora de refugo humano e de espetáculos, local onde identidades são invisibilizadas para caber em padrões preestabelecidos, espaço de (des)urbanização segregadora -, Alice se embrenha subversivamente pelas brechas e revela histórias e humanidades invisíveis para quem vive na superfície. Seu enfrentamento daquela cidade desconhecida é ao mesmo tempo destemido e questionador. Ela não apenas se apropria das ruas e resgata sua autonomia, mas dirige a essa experiência um olhar crítico que revela as contradições do espaço urbano. Quando sai para as ruas, procura sua posição de sujeito e inicia um processo de refletir, pensar, ver, escolher e enunciar. Alice, então, está ciente das diferentes camadas de invisibilização em que se insere - se, por um lado, essa invisibilização é opressora, por outro, é o que possibilita que Alice não seja objeto do olhar masculino nas ruas de Porto Alegre, subvertendo a lógica da política sexual do olhar através da sua flânerie pelo avesso da cidade. A transformação da personagem é evidente quando, no final do romance, já não procura mais por Cícero Araújo e tampouco recusa a identidade de pessoa em situação de rua. Seu comportamento se distancia da impessoalidade com que antes via (ou deixava de ver) essas pessoas. No avesso da cidade, Alice inventa sua cidadania: "andar com Lola dava-me direitos de cidadania pelas ruas, assimilavam-me como uma a mais entre eles" (REZENDE, 2014b, p. 237).

A vivência da personagem, ao não se fixar, ao se acostumar com a impermanência, remete ao conceito de subjetividade nômade, de Rosi Braidotti (2002), filósofa e professora na Universidade de Utretcht, na Holanda. O sujeito nômade é um mito, uma ficção política, uma figuração alternativa e metafórica escolhida por Braidotti porque possibilita pensar sobre e mover-se através de categorias estabelecidas. Baseada nessa figuração, Braidotti argumenta que as feministas - ou outras intelectuais críticas - são sujeitos nômades: são "aquelas que têm uma consciência periférica; esqueceram de esquecer a injustiça e a pobreza simbólica: sua memória está ativada contra a corrente; elas desempenham uma rebelião de saberes subjugados" (BRAIDOTTI, 2002, p. 10). É possível identificar essa rebelião no comportamento e na flânerie de Alice pelas ruas, em consonância com a definição que Braidotti confere às feministas.

Mais tarde, quando já está de volta ao apartamento, Alice relata que a sensação era como se a rua a agarrasse e a arrastasse, como um rio, da mesma forma que o flâneur é "atraído pelo ímã das massas que incessantemente o magnetiza" (BENJAMIN, 1994, p. 51): 
Saí andando, pensando em tudo o que ainda preciso escrever pra não sentir mais aquele frio na barriga, aquele aperreio que me dá quando me vejo de novo na rua, como se ela me agarrasse e não me quisesse mais largar, arrastando-me, rua-rio de novo (REZENDE, 2014b, p. 65).

Para Elkin (2016), seria ideal se não precisássemos dividir por gênero - o andarilho homem, a andarilha mulher, o flâneur, a flâneuse -, mas as narrativas do andar ou deambular pelas calçadas da cidade repetidamente deixam a mulher fora da experiência, portanto,

uma flânerie feminina - uma flâneuserie - não apenas muda o modo como nos movemos pelo espaço, mas intervém na organização do espaço em si. Nós reivindicamos nosso direito de perturbar a paz, de observar (ou não observar), de ocupar (ou não ocupar) e de organizar (ou desorganizar) o espaço nos nossos próprios termos 5 (p. 196 [tradução minha]).

Elkin (2016) defende a possibilidade da existência da flâneuse e afirma que essa personagem pode ser

uma escritora, uma artista, uma secretária ou uma au pair. A flâneuse pode estar desempregada. Ela pode não ser empregável. Ela pode ser uma esposa ou uma mãe, ou pode ser totalmente livre. Ela pode pegar o ônibus ou o trem quando estiver cansada. Mas na maior parte do tempo, ela anda a pé. Ela conhece a cidade ao vagar pelas ruas, investigando suas esquinas escuras, espiando atrás de fachadas, penetrando em pátios secretos. [...]. Ela viaja para fora e vai onde não deve ir; ela nos força a confrontar as formas como as palavras lar e pertencimento são usadas contra as mulheres. Ela é determinada, engenhosa e profundamente sintonizada com o potencial criativo da cidade e as possibilidades liberadoras de uma boa caminhada ${ }^{6}$ (p. 18 [tradução minha]).

Aqui, Elkin (2016) expõe a necessidade de confrontar as formas como as palavras lar e pertencimento são usadas contra as mulheres, de modo a cercear seus passos e limitar seus horizontes. Além disso, a importância de uma personagem flâneuse é a transformação das mulheres de objetos em sujeitos do olhar. Pollock (1988) argumentou que textos escritos por mulheres podem produzir diferentes posições dentro da política sexual do olhar. Sem essa possibilidade, às mulheres é negada a representação dos seus desejos e prazeres.

Pollock (1988) assegurou a importância de investir em significados diferentes daqueles ideologicamente produzidos para garantir a separação entre as esferas (pública e privada) e os conceitos associados à feminilidade.

Feminilidade não é a condição natural das pessoas. É uma construção histórica variável e ideológica de significados produzida por e para outro grupo social que obtém sua identidade e imaginada superioridade ao fabricar o espectro desse fantástico Outro ${ }^{7}$ (p. 71 [tradução minha]).

A feminilidade, para a autora, é uma ferramenta de regulação da sexualidade da mulher dentro de uma heterossexualidade doméstica e familiar. Segundo ela, uma das grandes formas de resignificar a feminilidade é a rearticulação dos espaços tradicionais para deixarem de ser espaços onde há um olhar dominante e se tornarem espaços de relacionamentos (POLLOCK, 1988, p. 87).

Para Wolff (1985), é preciso rever a historiografia e a sociologia da modernidade. O que falta na literatura, na visão da autora, é repensar a forma de olhar para os espaços privados e para aquelas mulheres que ocupavam as ruas (sempre tidas como não respeitáveis), "talvez um poema escrito pela mulher passante desconhecida sobre seu encontro com Baudelaire" ${ }^{8}$ (p. 47 [tradução minha]).

Para Elkin (2016), sugerir que não poderia haver uma versão feminina do flâneur é limitar as formas como as mulheres interagiram com a cidade às formas como os homens interagiram. Sua proposta é não tentar encaixar a mulher num conceito masculino, mas redefinir o próprio conceito. "Se olharmos para trás, descobrimos que sempre houve uma flâneuse passando por Baudelaire na rua"9 (ELKIN, 2016, p. 11 [tradução minha]).

\footnotetext{
5 "A female flânerie - a flâneuserie - not only changes the way we move through space, but intervenes in the organisation of space itself. We claim our right to disturb the peace, to observe (or not observe), to occupy (or not occupy) and organise (or disorganise) space on our own terms".

6 "She may be a writer, or she may be an artist, or she may be a secretary or an au pair. She may be unemployed. She may be unemployable. She may be a wife or a mother, or she may be totally free. She may take the bus or the train when she's tired. But mostly, she goes on foot. She gets to know the city by wandering its streets, investigating its dark corners, peering behind facades, penetrating into secret courtyards. [...]. She voyages out and goes where she's not supposed to; she forces us to confront the ways in which words like home and belonging are used against women. She is a determined, resourceful individual keenly attuned to the creative potential of the city and the liberating possibilities of a good walk".

7 "Femininity is not the natural condition of female persons. It is a historically variable ideological construction of meanings for a sign $W^{*} O * M^{*} A * N$ which is produced by and for another social group which derives its identity and imagined superiority by manufacturing the spectre of this fantastic Other".

8 "[...] a poem written by 'Ia femme passante' about her encounter with Baudelaire, perhaps".

9 "If we tunnel back, we find out there always was a flâneuse passing Baudelaire in the street".
} 
Flâneuse ou andarilha urbana, Alice questiona suas próprias noções de lar e de maternidade enquanto desbrava uma nova cidade pelos pés. Dessa forma, coloca em questão uma série de ideias pré-concebidas sobre a "feminização do lar" (Rosemary GEORGE, 1996), sobre pertencimento e maternidade, assim como sobre agenciamento da mulher no espaço urbano desconhecido. Ela se apropria dos espaços, aborda estranhos/as na rua, dorme onde for preciso.

Apesar de a experiência de Alice nas ruas ter se limitado aos quarenta dias anunciados no título - ou seja, as suas possibilidades, a sua mobilidade e a sua trajetória diferem muito daquelas das pessoas com quem conviveu nas ruas -, ainda assim ela foi sujeito de um olhar crítico e consciente da invisibilização de identidades selecionadas (os/as idosos/as, os/as "nordestinos/ as", as pessoas em situação de rua), o que confrontou com a ideia de uma cidade da superfície (cidade do espetáculo, gendrada, consumista, veloz e indiferente). No avesso da cidade, Alice encontrou pessoas com nome e história de vida que foram excluídas como "refugo humano" (BAUMAN, 2005). Assim, o romance de Maria Valéria Rezende aborda, costurando também pelo avesso do que parece ser uma história leve e engraçada, importantes questões sobre gênero e classe, inclusão e exclusão, identidades e invisibilização.

\section{Referências}

ACHUGAR, Hugo. "Culpas y memorias en las modernidades locales: balbuceos fragmentarios so pretexto de 'el flâneur' de Walter Benjamin”. Tonos Digital, n. 16, p. 1-17, 2008. Disponível em http:// www.tonosdigital.es/ojs/index.php/tonos/article/view/239/181. Acesso em 26/07/201 7. ISSN 1577-6921.

BAUMAN, Zygmunt. Vidas desperdiçadas. Tradução de Carlos Alberto Medeiros. Rio de Janeiro: Zahar, 2005.

BAUMAN, Zygmunt. Confiança e medo na cidade. Tradução de Eliana Aguiar. Rio de Janeiro: Zahar, 2009. (E-book)

BENJAMIN, Walter. "O Flâneur". In: BENJAMIN, Walter. Obras escolhidas III. Tradução de João Carlos Martins Barbosa e Hemerson Alves Baptista. São Paulo: Brasiliense, 1994. p. 33-65.

BLISS, Robert. 10 Hours of Walking in NYC as a Woman. Nova lorque, 2014. Disponível em https:// www.youtube.com/watch?v=b1XGPvbWnOA. Acesso em 16/11/2017.

BRAIDOTTI, Rosi. "Diferença, diversidade e subjetividade nômade". Tradução de Roberta Barbosa. Labrys - Estudos Feministas Labrys, Paris, Montreal, Brasília, n. 1-2, p. 1-16, 2002. Disponível em http://www.historiacultural.mpbnet.com.br/feminismo/Diferenca_Diversidade_e_Subjetividade_No made.pdf. Acesso em 15/08/2016. ISSN 1676-9651.

CANCLINI, Néstor. "Cidades e cidadãos imaginados pelos meios de comunicação". Opinião Pública, Campinas, v. 8, n. 1, p. 40-53, mai. 2002. Disponível em http://www.scielo.br/pdf/op/v8n1/ 14873.pdf. Acesso em 01/06/2019. ISSN 0104-6276. Doi: 10.1590/S0104-62762002000100003.

COMISIÓN INTERAMERICANA DE DERECHOS HUMANOS. Una mirada a la violencia contra personas LGBTI: comunicado à imprensa. Washington, n. 153, 2014. Disponível em http://www.oas.org/es/ cidh/lgtbi/docs/Anexo-Registro-Violencia-LGBTI.pdf. Acesso em 16/05/2017.

DALCASTAGNÈ, Regina. "Sombras da cidade: o espaço na narrativa brasileira contemporânea". Revista Estudos de Literatura Brasileira Contemporânea, Brasília, v. 21, p. 33-53, jan./jul. 2003. Disponível em http://repositorio.unb.br/handle/10482/9619. Acesso em 01/06/2019 Epub 01/01/2003. ISSN 2316-4018.

ELKIN, Lauren. Flâneuse: women walk the city in Paris, New York, Tokyo, Venice and London. New York: Farrar, Straus and Giroux, 2016. (E-book)

FÓRUM BRASILEIRO DE SEGURANÇA PÚBLICA. Visível e invisível: a vitimação de mulheres no Brasil. São Paulo, 2017. Disponível em http://www.forumseguranca.org.br/wp-content/uploads/2017/03/ relatorio-pesquisa-vs4.pdf. Acesso em 16/05/2017.

GEORGE, Rosemary. The politics of home: postcolonial relocations and twentieth century fiction. Berkeley: University of California Press, 1996.

HARVEY, David. "A Liberdade da Cidade”. In: HARVEY, David; MARICATO, Ermínia et al. Cidades rebeldes: passe livre e as manifestações que tomaram as ruas do Brasil. São Paulo: Boitempo, 2013. p. 27- 34. 
ITO, Carolina. "A cidade ideal das mulheres". Revista Trip, São Paulo, 2017. Disponível em http:// revistatrip.uol.com.br/tpm/arquitetura-e-planejamento-urbano-a-cidade-ideal-das-mulheres. Acesso em 10/05/2017. ISSN 1414-350x.

KOETZ, Vanessa. "Nas ruas e nas praças!". In: KOETZ, Vanessa; MARQUES, Helena; CERQUEIRA, Jéssica (Orgs.). Direito à cidade: uma visão por gênero. São Paulo: Instituto Brasileiro de Direito Urbanístico, 2017. p. 72-77.

MADARIAGA, Inés. "Urbanismo con perspectiva de género". Unidad de lgualdad y Género, Andalucía, módulo 4, p. 1-102, 2004. Disponível em https://www.juntadeandalucia.es/institutodelamujer/ institutodelamujer/ugen/sites/default/files/documentos/98.pdf. Acesso em 01/06/2019.

MASSEY, Doreen. Space, place and gender. Minneapolis: University of Minnesota Press, 2009.

MULVEY, Laura. "Visual pleasure and narrative cinema". In: ERENS, Patricia (Ed.). Issues in feminist film criticism. Bloomington: Indiana University Press, 1990. p. 28-40.

PICCINI, Mabel. "Sobre a comunicação nas grandes cidades". Opinião Pública, Campinas, v. 9, n. 2, p. 1-19, out. 2003. Disponível em https://periodicos.sbu.unicamp.br/ojs/index.php/op/article/ view/8641130/8641. Acesso em 26/07/2017. ISSN 0104-6276.

PINHEIRO, Leandro. "As periferias de Porto Alegre: suas pertenças, redes e astúcias. Bases para compreender seus saberes e dinâmicas éticas". Instituto Humanitas Unisinos, São Leopoldo, 2016. (Entrevista concedida à Patricia Fachin). Disponível em http://www.ihu.unisinos.br/159-noticias/ entrevistas/558958-periferias-de-porto-alegre-contingente-populacional-supera-o-de-muitascidades-gauchas-entrevista-especial-com-leandro-pinheiro. Acesso em 16/1 1/201 7.

POLLOCK, Griselda. Vision and difference: femininity and the histories of art. London: Routledge, 1988.

PREFEITURA DE SÃO PAULO. Secretaria Municipal de Desenvolvimento Urbano. "A mobilidade das mulheres na cidade de São Paulo". In: SPECIE, Priscila; VANETI, Vitor; MOUALLEM, Pedro. Informes urbanos, São Paulo, n. 25, p. 1-7, 2016. Disponível em https://www.prefeitura.sp.gov.br/cidade/ secretarias/upload/Informes_Urbanos/INFORME\%20MobSPMulher_rev.pdf. Acesso em 20/05/2017.

REZENDE, Maria Valéria. "Maria Valéria Rezende viveu na rua para escrever romance". Estadão, São Paulo, 2014a. (Entrevista concedida à Maria Fernanda Rodrigues) Disponível em http:// cultura.estadao.com.br/noticias/geral, maria-valeria-rezende-viveu-na-rua-para-escreverromance, 1161541 . Acesso em 23/07/2017.

REZENDE, Maria Valéria. Quarenta dias. Rio de Janeiro: Objetiva, 2014b.

SENNETT, Richard. O declínio do homem público: as tiranias da intimidade. Tradução de Lygia Araújo Watanabe. São Paulo: Companhia das Letras, 1988.

WOLFF, Janet. "The invisible flâneuse: women and the literature of modernity". Theory, Culture \& Society, v. 2, n. 3, p. 34-50, 1985.

WOOD, James. Como funciona a ficção. Tradução de Denise Bottmann. São Paulo: Cosac Naify, 2012.

WOOLF, Virginia. Um teto todo seu. Tradução de Vera Ribeiro. Rio de Janeiro: Nova Fronteira, 1985.

Daniela Schrickte Stoll (sstolldaniela@gmail.com) é doutoranda em Literatura no Programa de Pós-Graduação em Literatura da Universidade Federal de Santa Catarina e mestra em Literatura pela mesma universidade (2017). É membro da comissão editorial da Revista Anuário de Literatura (PPGL/UFSC) e integrante do Núcleo Literatual (Núcleo de Literatura Brasileira Atual Estudos Feministas e Pós-Coloniais de Narrativas da Contemporaneidade). Graduou-se em Arquitetura e Urbanismo (UFSC, 2010). 


\section{COMO CITAR ESSE ARTIGO DE ACORDO COM AS NORMAS DA REVISTA}

STOLL, Daniela Schrickte. "A flânerie de uma andarilha urbana". Revista Estudos Feministas, Florianópolis, v. 28, n. 2, e57230, 2020.

\section{CONTRIBUIÇÃO DE AUTORIA}

Não se aplica.

\section{FINANCIAMENTO}

O presente trabalho foi realizado com apoio do CNPq, Conselho Nacional de Desenvolvimento Científico e Tecnológico - Brasil.

CONSENTIMENTO DE USO DE IMAGEM

Não se aplica.

\section{APROVAÇÃO DE COMITÊ DE ÉTICA EM PESQUISA}

Não se aplica.

\section{CONFLITO DE INTERESSES}

Não se aplica.

LICENÇA DE USO

Este artigo está licenciado sob a Licença Creative Commons CC-BY Internacional. Com essa licença você pode compartilhar, adaptar, criar para qualquer fim, desde que atribua a autoria da obra.

\section{HISTÓRICO}

\section{Recebido em 23/05/2018}

Reapresentado em 18/12/2018

Aprovado em 19/06/2019 